\title{
OPPORTUNITIES AND CHALLENGES ON CONSERVATION OF AMBATARA PROTECTED AREA, SEDE MUJA DISTRICT, ETHIOPIA
}

\author{
Haile Zerfu Munaw \\ Ethiopian Environment and Forest Research Institute, P.O.BOX 2322 Addis Ababa, Ethiopia
}

Article DOI: https://doi.org/10.36713/epra4822

\begin{abstract}
Protected areas (PAs) are designated areas that are protected because of their environmental, cultural, or other worth. It plays a vital role in biodiversity conservation. Ethiopia has more many PAs, which cover $17.1 \%$ of the nation, protected to gain benefits for livelihoods at the local, regional and country level but the value obtained from the protected areas is very low.

An effective conservation of management practice for protected areas is one of the selected approach to make the harmony relationship between PAs and the local community in a given ecosystem. However, its practical implementation in protected areas through community method is the major challenge in Ethiopia. This study described the main opportunities and challenges of Ambatara protected Area (APA), Sede Muja District, Ethiopia.

Data were collected and organized by the household survey, key informant interview, field observation and focused group discussion (FGD) methods using both primary and secondary data sources in the form of qualitative, quantitative, or both from July 2019 to September 2019.

The results were explained the socioeconomic, opportunities and challenges. The establishment of community-based PA management in Ethiopia, proclamation and regulations of wildlife managements of Ethiopia, and natural recovery ability of the area were its potential opportunities whereas, local community wildlife conflict, conflicting between the APA management \& local community, inadequate coordination among stakeholders, and challenges \& threats of APA were the main challenges of APA conservation.
\end{abstract}

KEYWORDS: $A P A$, opportunities and challenges, local community, PA

\section{INTRODUCTION}

Protected areas are policy tools for conservation and sustainable use of natural resources, an essential tool to achieve conservation and sustainable development. It maintains biological and cultural diversity, helps to improve the livelihoods of the local community, provide the homelands for many indigenous peoples and bring countless benefits to society in general (Dudley, 2008).

The instituting and administration of PAs and the use of resources in and around them must be socially responsive and just. In addition, the growth of human activities in PAs, which are compatible with conservation objectives, should be accepted (IUCN, 1993) cited in (Trakolis, 2001). Nowadays, there are over 147,000 PAs in the world, covering the total area of 19.3 million $\mathrm{km} 2$, which is $13 \%$ of the Earth's total land area, or nearly the size of the entire African continent. On the other hand, only $0.8 \%$ of the global ocean area constitutes protected marine areas (Danijela, 2016).

In general, the distribution of natural resources and biodiversity does not respect international boundaries (Reader, 1999). Ever since individuals began to create settlements, they made boundaries to protect their territory and property. 


\section{EPRA International Journal of Research and Development (IJRD)

Animals, rivers, or mountain ranges do not recognize man made borders; they follow nature's design (Federation, 2010).

In particular, human activities remain to affect the capacity of Global systems to sustain life to the extent it is becoming the defining challenge for the 21st Century, and core to the Anthropocene concept (Steffen et al., 2011). On the other hand, the gazettement and management of protected areas will bring hardships to poor rural communities living in and around them (Infield \& Namara, 2001) due to loss of economic opportunities and exclusion from protected area resources (Infield \& Namara, 2001) and crop destruction \& livestock depredation by wild animals (Infield \& Namara, 2001).

Nowadays, in Ethiopia, efforts have been made for the establishment of the national park, wildlife sanctuaries and reserves gain benefits for livelihoods at local, regional and country level, but the value got from the PAs is very low when it is compared to other African countries. The majority of the PAs of the country face a severe threat from illegal poaching, deforestation, farming, and conflicts on rival park resources (Chanie and Tesfaye, 2015).

However, these PAs are degrading and facing, threats because of enlargement of population and settlement, illegal agricultural expansion, habitat loss and destruction, grazing, deforestation, soil degradation and misuse of natural resource in the country (Mulualem and Tesfahunegny, 2016). On the other hand, according to Ababa et al. (2012) cited by Getahun (2017) lack of comprehensive national and international policies, less commitment from government organs, shortage of finances, and requirements of education to raise awareness are the other challenges of PAs in the country.

The local community expands, settlement, deforestation, illegal resource extraction, farmland expansion, and grazing land, etc., are critically challenged APA, on the other hand, crop destruction and livestock predation have become the major wildlife conflicts. Moreover, the absence of or inefficient implementation policy, which fails to maintain the economic compensation with fair market value is an additional challenge in conservation. This study, carried out to identify the conservation challenges and opportunities on APA. Furthermore, no scientific studies have yet been conducted in the area to assess the opportunities and challenges with conservations of APA. Hence, this study is very critical to fill this gap.

Therefore, the objective of the study was to understand and investigate the conservation Opportunities and Challenges of Ambatara protected Area, Sede Muja District, Ethiopia.

\section{METHODOLOGY}

\subsection{Description of the study area}

The study was conducted on Ambatara Protected Area (APA), Sede Muja district, South Gondar zone, northwest Ethiopia, which is located approximately $740 \mathrm{~km}$ from Addis Ababa. Sede Muja district administered under South Gondar Administrative Zone, which lies within $11^{\circ} 08^{\prime} 57^{\prime \prime}-$ $11^{\circ} 40^{\prime} 27^{\prime \prime} \mathrm{N}$ latitude and $38^{\circ} 12^{\prime} 44^{\prime \prime}-38^{\circ} 38^{\prime} 40^{\prime \prime} \mathrm{E}$ longitude. APA is unique because of its biodiversity and woodland ecosystem. The APA has been selected to assess and investigate its interactions with the community.

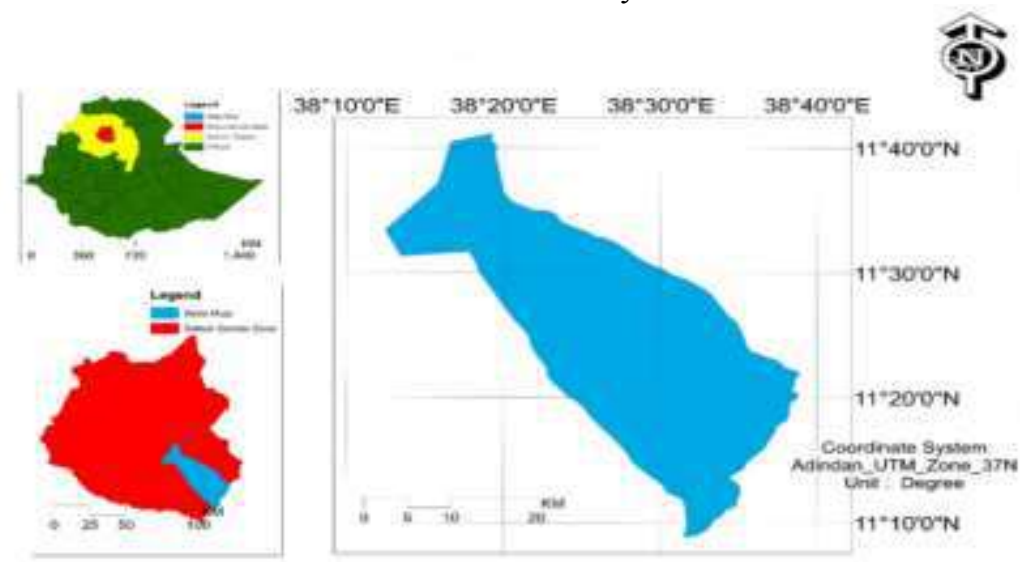

Figure 0-1 Map Sede Muja district study area. 


\section{EPRA International Journal of Research and Development (IJRD)

\subsection{Sampling design and method}

\subsubsection{Sampling design and size}

A randomly sampling (De Vos, 2011), 305 participants out of 1286 total residents aged 18 years or older (Snyman, 2013, 2014) living within $10 \mathrm{~km}$ and interacting with APA (Oldekop etal., 2016) at 95\% using a sample size (Israel, 2012) were interviewed.

$$
\text { formula } \mathrm{n}=\frac{\mathrm{N}}{\left(1+\mathrm{N}(\mathrm{e})^{2}\right)}
$$

Where ' $n$ ' is the number of selected sample size head households or respondents, ' $\mathrm{N}$ ' is the total household targeted population size and ' $\mathrm{e}$ ' is the level of precision.

\subsubsection{Data collection}

Data collection was conducted from July 2019 to September 2019 and included a household survey, key informant interview, field observation, and focused group discussion (FGD).

Household survey: Household heads were selected randomly to give an equal chance for all targeted residents. However, because of the rain and ploughing time, the majority of respondents were responded on the weekend. Information on age, education, distance from the park, economic activities, purpose of PA natural resources, view of compensation, attitudes towards the establishments of APA and others were collected. Before performing the interview, questionnaires were translated to Amharic language, and a half-day training was given for data collectors on how they can gather valuable data for the study. A clear explanation of the aim of the study was given to the interviewee to reduce the underestimation or overestimations of the study further on developing trust within the respondents. Preceding the start of the interview, the purpose of the study carefully explained to the respondent and their agreement to participate required (Kothari, 2004).

Key informant interview: Discussed with the district officials, APA, and stakeholders, and it was less strict formulated questionnaires that can offer the participants with a more relaxed to express their thoughts.

Focus Group Discussion (FGD): It was employed to collect qualitative information, and the group members in each FGD were consisted of 6-9, following (Mitchell and Branigan, 2000). FGD participants were selected based on their age, knowledge, and experiences within and around APA. Two FGDs were conducted; and each group consisted of two community leaders, two elders, two religious leaders, one expert from the APA, and one from the Sede Muja district. FGD was discussed on changes, problems, historical perspective and the importance of the APA establishment.

Field Observation: For achieving adequate and relevant information concerning local communities and establishments of APA, observation on what respondents were on their daily activities for their livelihoods, an outline of their living environment, and interaction information was assessed.

\subsubsection{Data analysis}

The data analysis was conducted by using Statistical Package for Social Sciences (SPSS) version 20. Descriptive statistics such as frequencies, percentages, sum and mean were utilized summarize respondents' demographic and socioeconomic profiles. Inferential statistics, particularly chi-square tests, were utilized in outlining relationships between variables, explaining relevant conclusions; and establishing the factors that influencing the local community's attitudes toward the establishment of APA.

\section{RESULT AND DISCUSSIONS}

\subsection{Socioeconomic characteristic}

After the replacement of the Emperor Ruling system in 1975, youth in rural areas of Ethiopia has been gaining farming land from local officials or their parents. Currently, however, because of limited farmland in the rural areas of Ethiopia have been become impossible to distribute for the young generation. Thus, elders have a better farmland size than compared to youth, except who retired and transferred their ownership of farmland to successors. Based on FDRE, 2005, Rural Land Administration and Use Proclamation (proc. $456 / 2005)$, farmers may have the right to get rural land (Art. 5.1). In addition, an individual above 18 years may get rural land; similarly, women have the claim to get Art. (5.2) (FDRE, 2005). The respondents lived in scattered settlement spread over around the Amabatara Protected Area (APA). The majority of the respondents were from the age group between 18-38 years (42.6\%); followed by $39-59$ years $(37.7 \%)$. These two groups covered $80.3 \%$ of the sample among the selected respondents (Table 3$1)$.

The percentage of male respondents were $93.44 \%$, and the rest $6.57 \%$ was females. The total average family size was 4 , with a range of from 2-9. Similarly, within age groups of 18-38, 39-59 and $>=60$, their average family size were $5.14,5$ and 3.05 respectively. Nearly one-third of respondents were uneducated farmers while the rest of them could read and write Amharic, the national language of Ethiopia. Respondents were had 2.34, 2.22 and 1.38 


\section{EPRA International Journal of Research and Development (IJRD)

hectares of average farmland size, and also, 14.3, 12.86 and 7.88 average livestock sizes for age groups of $18-38,39-59$ and $>=60$, respectively. The national land use survey shows that the average household farm size in Ethiopia is 1.22 hectares, but $57 \%$ of the households have farm sizes less than one hectare (CSA, 2012a).

Table 0-1 Socioeconomic characteristics of the respondents

\begin{tabular}{|c|c|c|c|c|c|c|c|}
\hline \multirow{2}{*}{$\begin{array}{l}\text { Age } \\
\text { Class }\end{array}$} & \multicolumn{4}{|c|}{ Sex } & \multirow{2}{*}{$\begin{array}{l}\text { Average } \\
\text { Family size }\end{array}$} & \multirow{2}{*}{$\begin{array}{l}\text { Average farmland } \\
\text { (ha) }\end{array}$} & \multirow{2}{*}{$\begin{array}{l}\text { Average } \\
\text { Livestock } \\
\text { Size }\end{array}$} \\
\hline & Female & Male & $\mathrm{N}$ & Total \%) & & & \\
\hline $18-38$ & 8 & 122 & 130 & $42.6 \%$ & 5.14 & 2.34 & 14.3 \\
\hline $39-59$ & 8 & 107 & 115 & $37.7 \%$ & 5 & 2.22 & 12.86 \\
\hline$>=60$ & 4 & 56 & 60 & $19.7 \%$ & 3.05 & 1.38 & 7.88 \\
\hline Total & 20 & 285 & 305 & $100 \%$ & - & & \\
\hline
\end{tabular}

\subsection{Opportunities in APA conservation}

1.4.1 Establishment of communitybased PA management in Ethiopia

Ethiopia owns considerable biodiversity and natural resources, as well as many endemic species. However, its wildlife conservation policy has been changing with the continuous changing regimes. It has had limited success in protecting some of these natural assets since establishing conservation and PA program in 1965, because of the nation's lengthy engagement in numerous armed conflicts. Moreover, given the potential of the park and biodiversity, the extent of protected areas and biodiversity conservation of the country is negligible missing protected area networks and management plans (Biodiversity Indicators Development National TaskForce, 2010).

The new management approach gives the considerations of local community rights and benefits In addition, it ensures the sustainable conservations of protected areas, which are acceptable by the APA management and local community. To ensure the success of conservation, supporting the relationship between the community and protected area is crucial. However, failure to ensure participation residents, the absence of alternative livelihood, and widespread poverty, human settlement, grazing, absence of legally recognized boundaries of protected areas were persistent in the Ethiopian protected area (Eshetu, 2014) where local community used to utilize the land until they were declared protected areas.

\subsubsection{Proclamation and Regulations of Wildlife Managements of Ethiopia} Proclamation Number 541/2007 development, conservation and utilization of wildlife and regulation No 163/2008 wildlife development, conservation and utilization is other opportunities for management of protected areas. To attain, the objective of the conservation and management of PA, the declaration of the proclamation and regulation of wildlife development and utilization has paramount importance. It gives outstanding highlighting to the triple role of the government, the community and investors and developmental NGOs (Federal Democratic Republic of Ethiopia( FDRE), 2008). The proclamation and regulation of wildlife conservations have a positive contribution to the establishment and conservations of APA.

\subsubsection{Natural recovery ability of the area}

According to the field observations and the district evidences, the Ambatara Protected Area (APA) has many different natural resources. Its climatic condition is very suitable for the degraded most part to be recovered or regenerated within a short period. The long season of the weather condition is a dry season from October to May whereas from June up to September its rainy season. The local growing tree species are adapted to the local adapted the weather condition. The local optimum climatic conditions might be made helpful to increase their growth and just protecting the local area from human or other contacts will be helped in rehabilitating within a short period.

In general, the APA management should be initiating and implementing suitable conservation strategies considering the opportunities to make the sustainable conservations of the APA with satisfying the aspirations of the local community to make the coexistence of the APA and the local community.

\subsection{Challenges of APA conservation}

Ethiopia is rich with biodiversity in nature, but little in capacity for biodiversity conservation or protected area management. Critically, it is expected that over 110 million people in Ethiopia, $85 \%$ in rural areas, and $80 \%$ in the highlands. The massive are almost entirely dependent on natural resources for livings. As a result, 97\% of the original highland vegetation has already been lost in current decades because of encroaching agriculture, grazing and settlement by agro-pastoral communities. Poor 


\section{EPRA International Journal of Research and Development (IJRD)

resource-dependent local community is still raising in Ethiopia, both within and nearby National Parks and other areas with high biodiversity value. Finally, mountain ecosystems are the most susceptible on the earth to climate change over the next 50-90 years. Implementing sustainable and climate-smart conservation for the benefit of biodiversity and people alike is of utmost importance (Mutanga and Vengesayi, 2015).

Unluckily, Ethiopia's ability for conservation management is one of the least in the world after decades of underinvestment by the international community and Government alike. The Ethiopian Wildlife Authority's budget for PAs is the third least internationally (just $0.5 \%$ of the average) and is $3 \%$ of that took necessary for effective management. However, in current years the relationship between the environment and poverty are, becoming higher profile and this has elevated the environment up the political agenda. In addition, there is a substantial increase in political will for biodiversity conservation (Chanie and Tesfaye, 2015). In APA, the following challenges are among the frequently occurred.

\subsubsection{Local community -wildlife conflict}

The majority of the local community members living within and around APA are farmers and mainly dependent on subsistence farming and livestock keeping. Because of their farmland and grazing land found closely in the habitats of wild animals living within APA massive crop destruction and livestock predations are the most common local community-wild life conflicts. The crop damages were mostly by monkeys and apes whereas the livestock predations were by foxes.

Indeed, APA conservation has many purposes, but crop destruction and livestock predation become common local community-wildlife conflicts. Moreover, the absence of or inefficient implementation policy, which fails to maintain the economic compensation for their fair market value is an additional challenge in the conservation of APA.

Conflicts in the use of natural resources among the community living nearby to the PA and tourism development have increased in the current years, because of changes in land use and associated new concepts about wildlife resource management and utilization. Human-wildlife conflict is a major concern of most people living next to protected areas in developing countries due to their subsistent live (Reddy and Workneh, 2014).

Human wildlife challenges start when livestock try to win food and water against the will of wildlife. Livestock herding and agriculture is the main source of revenue and livelihood in undeveloped countries, human-wildlife conflict is more common in the region for natural resource consumption, which brought wildlife under severe threat. (Woyesa, 2016).

Human-wildlife conflicts have been more intense in recent decades, because of exponential human population growth and economic activities. The highest degree of conflicts tends to occur where humans live nearby to PAs and crop damage is the most predominant form of human-wildlife conflict across the country (Hansilo and Tiki, 2017).

In Ethiopia, the majority of whose farming activities are poor, local subsistence farming communities, and in some cases, commercial farms nearby to wildlife habitats often impacted by the existence and abundance of wild pest animal species. Crop destruction is a rising cause of economic loss and local frustration in subsistence farming settings and also inspires negative attitudes towards species of conservation value. In Ethiopia, different PAs face several challenges because of the rising populations, border conflicts, and recurring drought. Many people in Ethiopia are rural, who needs access to grazing lands (Teshome and Girmay, 2017).

\subsubsection{Conflict between the APA management and local community} Protected area involves a conflict of interests and international outlooks among different entities. In addition, the consistency of competing interests over the territory at local, regional and national levels, there are apparent evidences of divergence in international views on the approaches to conservation and viewpoints on development.

The demand of the local community members to use the APA resources increased, but in the reverse, the APA resources diminished from time to time. Because of this, the needs of the local community and the conservations of APA are becoming opposite each other for. Inadequate of income for their livelihoods enforce the local community to expand farmland, grazing land, extractions of construction materials and fuelwoods. This led to overexploitation of the natural resources led to deforestations, degradation, frequent drought, etc. On the other hand, the APA management aims to conserve the resources by imposing restrictions against the free access of the local community. These situations led to conflict between the APA management and local community.

According to (Abelieneh, 2017), the establishment of the park significantly affects the local peoples' livelihoods and makes a critical challenge for the park administrators and other local government bodies and vice versa in case of the Alatish national park. Thus, unless the government 


\section{EPRA International Journal of Research and Development (IJRD)

bodies reconsider the issue in the park planning and administration process and then make some adjustments, which are important for the biodiversity conservation and well- being of the local people, both the park sustainability and livelihood sustainability will be greatly at risk.

\subsubsection{Resources utilization and conflict}

According to respondents' the local community directly or indirectly dependent on the dependent on APA resources, which caused to the conflicts between APA management staff and the local community. According to the APA manager, all of the surrounding residents of the APA were farmers and low level of income. Again, all residents have no distinct land for their livestock. Therefore, they satisfy their livelihood fully or partially dependent on the use of APA resource table (3-2).

Further, focus group discussions and individual interviews revealed that the conflicts often faced were mainly two types. The first was a minor conflict between APA resource users with the regard to the use of APA resource products. Regards to this, some informants specified that they were disappointed because of the restoration imposed over the previous unlimited access. This unfriendly feeling exaggerates and create problems on the APA management. The second one were associated with the border demarcation. At the time of field observation, the APA located closely with the majority of the local community. During the border, the demarcation process suitable farmland, which is found inside or near the APA and the massive grazing land included into the side of the APA. The local community was practiced in using these resources from the APA.
The majority of the local community and the APA staff were agreed that the conflicts between the APA and local community has decreased during the rainy season and this was mainly due to a reduction of the firing and hunting, availability of sufficient amount of forage sources for the animals and government interferences settle the problems. In addition, most respondents have agreed that community elders, religious leaders, respected individuals and government bodies managed conflicts. This is similar to earlier reports that the inter-clan and community conflict can often be solved using traditional and social organizations. The same authors further suggested that traditional and institutions have a key role to play in resolving conflicts, the management of natural resources and to maintain peace between local community and protected areas.

Respondents were asked about their dependency on APA resources and their understanding of its conservation. Fully dependent and partly depend were mentioned $21.33 \%, 59.67 \%$ respectively by the respondents. However, the $9.8 \%$ were unaware of why the government established the APA Table (3-2). However, the 19\% were not all dependent on APA resources.

In general, $81 \%$ of the respondents were dependent on APA resources without considerable difference between the two aged groups. Hoverer, 19\% respondents were not at all dependency on APA resources. Respondents age group 39-59 years, 32.46\% dependent on APA resources, and their responses were shared by $31.47 \%$ of aging group 18-38, whereas $17.77 \%$ of respondents were dependent on aged group $>=60$.

Table 0-2 Dependency on APA resources

\begin{tabular}{llllll}
\hline Dependency on APA & N (305) & \multicolumn{4}{c}{ Age group } \\
\cline { 3 - 6 } resources & & $\mathbf{1 8 - 3 8}$ & $\mathbf{3 9 - 5 9}$ & $\mathbf{> = 6 0}$ & Total \\
\hline Fully depend & 65 & $7.54 \%$ & $10.49 \%$ & $3.28 \%$ & $21.33 \%$ \\
Partly depend & 182 & $23.93 \%$ & $21.97 \%$ & $13.77 \%$ & $59.67 \%$ \\
Not at all & 58 & $11.15 \%$ & $5.25 \%$ & $2.6 \%$ & $19 \%$ \\
\hline
\end{tabular}

The local community described that access to the natural resources such as construction wood, fuel wood and others before and after the establishment of the PA. However, access to the grass found to be better after the establishment of the
APA Table (3-3 \& 3-4). Respondents were responding easy, medium, and difficult and neutral based on their accessibility to use the specified natural resources before and after the establishments of the APA. 


\section{EPRA International Journal of Research and Development (IJRD)}

Volume: 5 | Issue: 7 | July 2020

- Peer Reviewed Journal

Table 0-3 Responses of local community towards access NR to before the establishment of the PA.

\begin{tabular}{lllllll}
\hline Natural resources & $\begin{array}{l}\text { Accessibility } \\
\text { to use }\end{array}$ & $\mathbf{N}(305)$ & \multicolumn{4}{c}{ Age group } \\
\cline { 3 - 6 } Construction wood & Easy & 138 & $23.8 \%$ & $14.3 \%$ & $7.1 \%$ & $45.2 \%$ \\
& Medium & 88 & $12.3 \%$ & $12.1 \%$ & $4.5 \%$ & $28.9 \%$ \\
& Difficulty & 49 & $2 \%$ & $7.8 \%$ & $6.3 \%$ & $16.1 \%$ \\
Fuelwood & Neutral & 30 & $4.5 \%$ & $3.5 \%$ & $1.8 \%$ & $9.8 \%$ \\
& Easy & 131 & $17.8 \%$ & $13.9 \%$ & $11.1 \%$ & $42.8 \%$ \\
& Medium & 92 & $13.7 \%$ & $11.8 \%$ & $4.6 \%$ & $30.1 \%$ \\
Grass & Difficulty & 43 & $7.3 \%$ & $5.7 \%$ & $1.1 \%$ & $14.1 \%$ \\
& Neutral & 39 & $3.8 \%$ & $6.3 \%$ & $2.9 \%$ & $13 \%$ \\
& Easy & 200 & $29.4 \%$ & $23.8 \%$ & $12.3 \%$ & $65.5 \%$ \\
Others & Medium & 81 & $8.5 \%$ & $12.3 \%$ & $5.9 \%$ & $26.7 \%$ \\
& Difficult & & - & - & - & - \\
& Neutral & 24 & $4.7 \%$ & $1.6 \%$ & $1.5 \%$ & $7.8 \%$ \\
& Easy & 165 & $22.8 \%$ & $19.6 \%$ & $11.7 \%$ & $54.1 \%$ \\
& Medium & 108 & $13.5 \%$ & $15.9 \%$ & $5.9 \%$ & $35.3 \%$ \\
& Difficult & 22 & $5.1 \%$ & - & $2.1 \%$ & $7.2 \%$ \\
& Neutral & 10 & $1.2 \%$ & $2.2 \%$ & - & $3.4 \%$ \\
\hline
\end{tabular}

Table 0-4 Responses of local community towards access NR to after the establishment of the PA

\begin{tabular}{lllllll}
\hline Natural resources & accessibility & $\mathrm{N}$ & \multicolumn{3}{c}{ Age group } \\
\cline { 5 - 7 } & to use & $(305)$ & $18-38$ & $39-59$ & $>=60$ & Total \\
\hline Construction & Easy & - & - & - & - & - \\
wood & Medium & 115 & $12.9 \%$ & $18.3 \%$ & $6.3 \%$ & $37.5 \%$ \\
& Difficulty & 160 & $26.3 \%$ & $14.6 \%$ & $11.7 \%$ & $52.6 \%$ \\
Fuelwood & Neutral & 30 & $3.4 \%$ & $4.8 \%$ & $1.7 \%$ & $9.9 \%$ \\
& Easy & - & & & & \\
& Medium & 183 & $26.4 \%$ & $23.9 \%$ & $9.7 \%$ & $60 \%$ \\
Grass & Difficulty & 122 & $16.2 \%$ & $13.8 \%$ & $10 \%$ & $40 \%$ \\
& Neutral & - & & & & \\
& Easy & 38 & $7.8 \%$ & $4.4 \%$ & $2.1 \%$ & $12.3 \%$ \\
\multirow{5}{*}{ Others } & Medium & 108 & $16.7 \%$ & $13.9 \%$ & $4.9 \%$ & $35.5 \%$ \\
& Difficult & 149 & $14.7 \%$ & $21.4 \%$ & $12.7 \%$ & $48.8 \%$ \\
& Neutral & 10 & $3.4 \%$ & - & - & $3.4 \%$ \\
& Easy & 77 & $11.2 \%$ & $9.1 \%$ & $4.9 \%$ & $25.2 \%$ \\
& Medium & 84 & $17.8 \%$ & $7.9 \%$ & $1.9 \%$ & $27.6 \%$ \\
& Difficult & 136 & $13.6 \%$ & $18 \%$ & $12.9 \%$ & $44.5 \%$ \\
& Neutral & 8 & & $2.7 \%$ & & $2.7 \%$ \\
\hline
\end{tabular}

1.5.2.2 Conflict over the use of APA resources had not conflict over the use of APA resources Table Respondents were asked about their conflict (3-6).

over the use of APA resources and their understanding of its conservation. Often and sometimes were mentioned $32.13 \%$ and $60.33 \%$ respectively by the respondents. However, the $7.54 \%$ 


\section{EPRA International Journal of Research and Development (IJRD)}

Table 0-5 Respondents view on the conflict over the use of APA resources

\begin{tabular}{llllll}
\hline Conflict over the use of APA resources & \multirow{N}{*}{$\mathrm{N}(305)$} & \multicolumn{4}{c}{ Age group } \\
\cline { 3 - 6 } & & $18-38$ & $39-59$ & $>=60$ & Total \\
\hline Often & 98 & $14.75 \%$ & $13.44 \%$ & $3.9 \%$ & $32.13 \%$ \\
Sometimes & 184 & $25.57 \%$ & $20.66 \%$ & $14.1 \%$ & $60.33 \%$ \\
No & 23 & $2.3 \%$ & $3.6 \%$ & $1.64 \%$ & $7.54 \%$ \\
\hline
\end{tabular}

1.5.3 Inadequate Coordination among Stakeholders

The main stakeholders associated with APA are local community, Zone and Regional Administration, the Federal government, EWCA, NGOs and other Educational Institutions. Coordination among the stakeholders and associated entities in APA are very weak. The weakness starts from the lowest APA administration levels extends to the top of the federal government structures.

Absence of a single administrative body taking responsibility for the APA administrations negatively influences its conservation. From the Federal level Environment Forest and Climate Change Commission, Ministry of agriculture \& natural resource, and ministry of culture \&tourism whereas at regional levels, the Amhara regional agricultural office and natural resources protection officials overlaps their mandates regarding implementing and administering protected areas. Because of this, there is no a single responsible governmental system, taking responsibility in PA administration. The common activities such as planting seedlings, constructions of watersheds etc., were performed by temporary delegates, which could low and weak implementation power. In addition, because of the absence of consistent conservation strategies, timely considering local community rights and benefits failed to manage the concerned stakeholders and local community together. Hence, to make sure the sustainable conservations of APA suitable conservation strategies and responsible government structure as well as to be considered the wills and aspirations of the local community is critically important.

According to (Woyesa, 2016) the opposing attitudes in NNP primarily about the size of the park, the fate of the community, the legal status of the park boundary and the conservation scheme to implement both states in a difficult state to negotiation and place the park in difficult situation to achieve conservation objectives. Conservation without the permission and participation of communities affected by the APA establishment in the Sede Muja district deceased sense of ownership and made negative perception towards any change of government to succeed in the conservation effort.

\subsubsection{Challenges and threats of APA}

The The common conservation problems of the APA as mentioned by the majority of the respondents were overgrazing, farmland expansion, settlement, fuelwood collection, grass cutting, deforestation, population expansion, accessibility \& resource extraction, conflicts between the APA management(mgt) \& local community( LC), excessive harvesting and uses of other resources, livestock predation, and crop damage. These problems caused to the soil erosion, vegetation degradation, wildlife depletion and deforestation.

Indeed, APA conservation has many purposes, but crop destruction and livestock predation become common local community-wildlife conflicts. Moreover, absence of or inefficient implementation policy, which fails to maintain the economic compensation with their fair market value is an additional challenge in the conservation of APA. According to the respondents in addition to conservation problems of natural resources, lack of clean drinking water, lack of communication, inadequate livelihood and insufficient income are the main problems of the local community in and around the APA. The poor people in rural areas depend directly on natural resources, which might lead to the loss of these resources (Brodnig, 2006).

Local communities present that basic social provisions such as electricity, roads and drinking water supplies are either missing or inadequate in PA as the most pressing challenges. They reported that GO's/NGOs seeking to provide social provisions to the community were prevented by the park management with claims that it is not allowed to establish or expand social provisions in a national park's territory (Astella, 2013). Lack of electricity, roads and water supplies prompts the people to opt for other means of acquiring or supplementing livelihood that are still against the park's rules and regulations (Astella, 2013). Fig (3-2) illustrates the major challenges of the APA as preceding the respondents. 


\section{EPRA International Journal of Research and Development (IJRD)

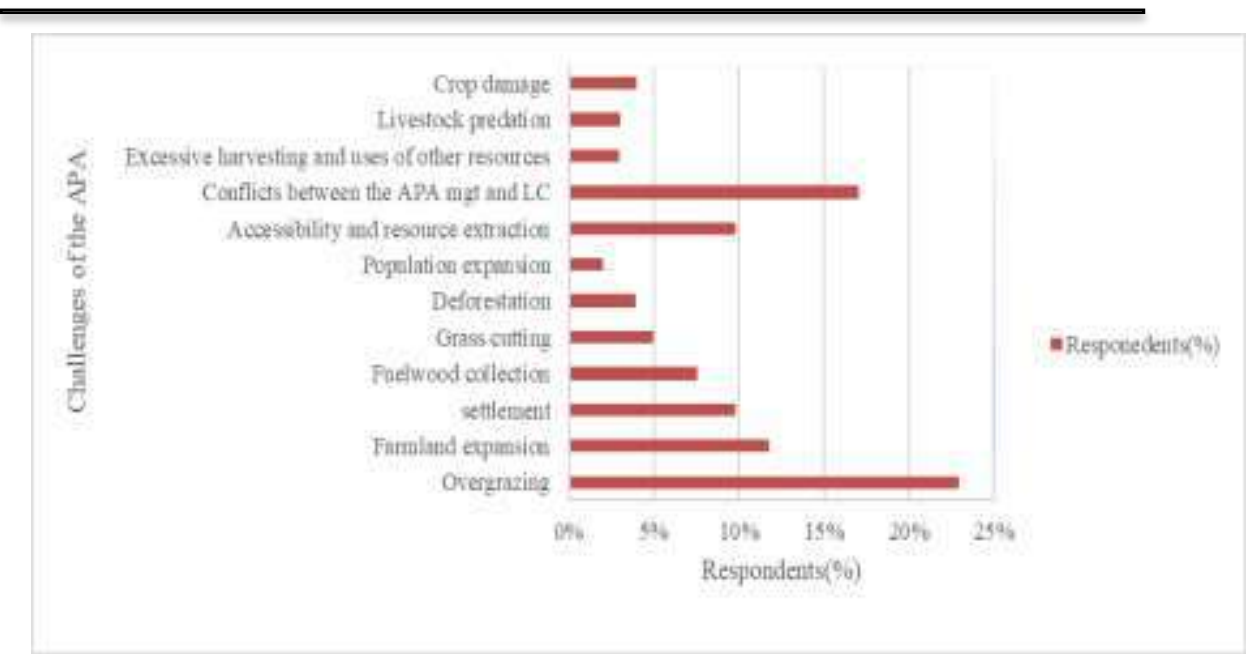

Figure 0-1 Major challenges of the APA

Identifying both the potential opportunities and serious challenges are important to take important measures and considering the factors in initiating and implementing sustainable conservation strategies. In addition, creating awareness, teaching purpose of establishment \&conservation objectives, giving sufficient compensation for those injured individuals at the right time, implementing sustainable management strategies, initiating incentives and making partnership, and introduce alternative income methods are important for the sustainable coexistence of both the local community and APA.

Therefore, the local community -wildlife conflict, the conflict between the APA management \& local community, inadequate coordination among stakeholders, and challenges \& threats of APA were the main challenges of APA conservation. Hence, the APA management should consider these critical challenges in their initiating and implementing conservation management strategies to make sure the coexistence of both APA and the local community. This may help create sense of ownership on the part of the communities settled surrounding the APA. Moreover, this may help mitigate the conflicts that could happen between the interest of the local community and the PA.

\section{CONCLUSION AND RECOMMENDATION}

The study was conducted on Ambatara Protected Area (APA). APA is recently established PA in Ethiopia, which is located in Sede Muja district, South Gondar zone, northwest Ethiopia. The study investigated and identified the opportunities and challenges of Ambatara protected Area, Sede Muja District, Ethiopia.
Establishment of community-based PA management in Ethiopia, proclamation and regulations of wildlife managements of Ethiopia, and natural recoverability of the area were its potential opportunities whereas, local community -wildlife conflict, conflict between the APA management \& local community, inadequate coordination among stakeholders, and challenges \& threats of APA were the major challenges of APA conservation. Moreover, because of the human interference the natural resources base of the APA has been overexploited and exposing numerous challenges. Expansion of local community settlement, farmland expansion, excessive grazing, deforestation, natural resources extraction, poor land management technique directly threats the existence of APA. The majority of respondents had generally partly depend on APA resources, but few residents are still extracting natural resources illegally, farmland expansion, and grazing land, etc., which are the most critical challenges.

Respondents were responding easy, medium, and difficult and neutral based on their accessibility to use the specified natural resources before and after the establishments of the APA. Indeed, APA conservation has many purposes, but crop destruction and livestock predation become common local community-wildlife conflicts. Moreover, absence of or inefficient implementation policy, which fails to maintain the economic compensation with their fair market value is an additional challenge in the conservation of APA.

Generally, the APA management and other concerned body should identify and utilize potential opportunities to make sure the coexistence of both APA and the local community. On the other hand, identifying and understanding the main challenges of the threats APA and as well as the problems of the 


\section{EPRA International Journal of Research and Development (IJRD)}

local community is critical to protect from destruction and safely conserve the APA with maintaining the benefits of the local community without affecting the sustainability of the resource uses.

In general, the APA management should be initiating and implementing suitable conservation strategies considering the opportunities to make the sustainable conservations of the APA with satisfying the aspirations of the local community to make sure the coexistence of the APA and the local community. Similarly, the local community -wildlife conflict, the conflict between the APA management \& local community, inadequate coordination among stakeholders, and challenges \& threats of APA were the main challenges of APA conservation. Hence, the APA management should consider these critical challenges in its initiating and implementing conservation management strategies to make sure the coexistence of both APA and the local community.

\section{REFERENCES}

1. Assefa Abelieneh, Genanew Agitew and Kibrom Adino. (2017). Impacts and Prospects Of Alatish National Park For Local Livelihoods Sustainability; North Western, Ethiopia.

2. Astella, B. (2013). Multiple Enactments of Abijata Shalla Lakes National Park, Ethiopia.

3. Biodiversity Indicators Development National TaskForce. (2010). Ethiopia: Overview of Selected Biodiversity Indicators. Addis Ababa. Pp. 48 .

4. Birhan, M. \& Gebreyes, G. (2015). Economic Contribution of Wildlife Management and Ecotourism in Ethiopia. , 6(5).Veterinary Science \& Technology Review on Problems, Prospects and.

5. Brodnig, G. (2006). Biodiversity Conservation and the Millennium Development Goals: Toward Sustainable Development. Regional Development Dialogue.

6. Chanie, S. and Tesfaye, D. (2015). Threats of biodiversity conservation and ecotourism activities in Nechsar National Park, Ethiopia. , 7(2), pp.130-139.

7. CSA. (2012a). Agricultural sample survey 2011/2012, Volume IV: Report On Land Utilization, Central Statistical Agency, Addis Ababa, Ethiopia (2012).
8. Danijela A. (2016). Evaluation of Protected Area Management Effectiveness - An Overview.

9. De Vos, A.S., Strydom, H., Fouché, C.B., \& Delport, C.S.L. (2011). Research at grassroots (4th ed.). Pretoria: Van Schaik.

10. Dudley, N. (ed.). (2008). Guidelines for applying protected area management categories. IUCN, Gland,Switzerland.

11. Eshetu, A.A. (2014). Forest resource management systems in Ethiopia : Historical perspective.

12. Federal Democratic Republic of Ethiopia (FDRE). (2005). Rural Land Administration and Land Use Proclamation, Proclamation No. 456/2005. Negarit Gazeta. Year 11, No. 44.

13. Federal Democratic Republic of Ethiopia( FDRE). (2008). Proclamation Number 541/2007 development, conservation and utilization of wildlife and regulation No 163/2008.

14. Federation, E. (2010). Following Nature's design, promoting cross-border cooperation in nature conservation.

15. Getahun Shanko Mamo. (2017). Review on Challenges and Opportunities of Protected Area Management in Ethiopia.

16. Getahun, B.T. and Yeshanew, Y.A. (2016). Sustainable ecotourism potentials and its challenges in Ethiopia: The Awash National Park in Focus. . International Journal of Humanities and Social Science Research, 2(4), pp.2455-2070.

17. Hansilo, D.D. and Tiki, L. (2017). Challenges of human settlement on wildlife in Bale Mountains National Park, Southeast Ethiopia.

18. Hillman JC, . (1993). Ethiopia: Compendium of wildife conservation information.Vol.2. NYZS and EWCO, Addis Ababa, Ethiopia. p. 580. Vol.2.

19. Infield $M$ \& Namara A. (2001). Community attitudes and behavior towards conservation: an assessment of community conservation program around Lake Mburo National Park, Uganda. Oryx 35(1):48-60. http://dx.doi.org/10.1017/S0030605300031537.

20. Israel GD. (2012). Determining Sample Size, Agricultural Education and Communication Department, Florida Cooperative Extension Service, Institute of Food and Agricultural Sciences, University of Florida. 


\section{EPRA International Journal of Research and Development (IJRD)}

21. IUCN. (1993). Parks for life. Report of the IVth World Congress on National Parks and Protected Areas, pp 252.

22. Kothari, C.R. (2004). Research Methodology: Methods and Techniques, second ed. New Age International, New Delhi, India.

23. Mitchell, K. and Branigan, P. (2000). Using focus groups to evaluate health promotion interventions. Health Education 100:261-268.

24. Mulualem, A.G. and Tesfahunegny, W. (2016). Review of Key Wildlife Threats Factors from Literature and Observation Perspectives: A Way Forward for Sustainable Wildlife Genetic Resource Conservation Practices in Ethiopia. , 3(5), pp.1-12.

25. Mutanga, C.N. and Vengesayi, S. ( 2015). Community perceptions of wildlife conservation and tourism : A case study of communities adjacent to four protected areas in Zimbabwe. .

26. Oldekop, J.A., Holmes, G., Harris, W.E., Evans, K.L. (2016). A global assessment of the social and conservation outcomes of protected areas. Conserv.Biol. 30(1), 133e141.

27. Reader, J. (1999). Africa, A Biography of the Continent, Random House Inc.

28. Reddy, R.U. \& Workneh, S. (2014). Conflicts between the conservation of Elephant and Human activities : In the case of Babile Elephant Sanctuary( BES ), Ethiopia.,pp.25-29.

29. Reddy, R.U. and Workneh, S. (2014). Conflicts between the conservation of Elephant and Human activities: In the case of Babile Elephant Sanctuary (BES), Ethiopia.
30. Snyman, S. (2013). High-end ecotourism and rural communities in southern Africa: a socioeconomic analysis. Unpublished PhD. thesis. University of Cape Town: School of Economics.

31. Snyman, S.L. (2014). Assessment of the main factors impacting community members' attitudes towards tourism and protected areas in six southern African countries. Koedoe, 56(2), 1-12.

32. Steffen, W., Persson, A., Deutsch, L., Zalasiewicz, J., Williams, M., Richardson, K., Crumley, C., Crutzen, P., Folke, C., Gordon, L., Molina, M., Ramanathan, V., Rockström, J., Scheffer, M., Schellnhuber, H.J. \& Svedin, U. ( 2011). The Anthropocene: from global challenge to planetary stewardship. Ambio, 40, 739-761.

33. Teferra, F. \& Beyene, F. ( 2014). Indigenous claims and conflicts in managing the AbijataShalla Lakes National Park, Ethiopia. International Journal of Biodiversity Science, Ecosystem Services \& Management, 10(3),.

34. Teshome, and Z. Girmay,. (2017). HumanWildlife Conflict : Challenge and Management in Ethiopia: A. , 89, pp.5004-5009.

35. Trakolis, D. (2001). Local people's perceptions of planning and management issues in Prespes Lakes National Park, Greece. Environmental Management, Vol. 61, pp227-241.

36. Woyesa T. (2016). Retrospect and Prospects of Combining Conservation and Development in Nechsar National Park, Southern Ethiopia. Intel Prop Rights. 4: 169. 